\title{
History as an Enemy and an Instructor Lessons Learned from Haiti, 1915-34
}

\author{
Christopher Davis, PhD
}

\begin{abstract}
As Haiti and other nations in the Caribbean and Latin America experience increasing instability, and the United States increases its naval presence in the region, history offers important lessons for future U.S. involvement. An exploration of the tactical innovations of the Marine Corps and of the influence of national history on the Haitian insurgencies during the U.S. occupation of Haiti (1915-34) reveals the significance of history in either achieving or curtailing military goals.
\end{abstract}

Keywords: U.S. military history, Haitian insurgencies, counterinsurgency, tactical innovation, culture, Haiti, U.S. involvement in Haiti, occupation of Haiti, Marines in Haiti

\section{Political Instability in Haiti and Its Causes}

ince 2019, the Latin American and Caribbean region has experienced a $\mathbf{S}$ sharp increase in the political and economic instability of several of its nations, some of which had previously been the focus of U.S. military interventions during the early twentieth century under similar circumstances. Haiti in particular, though no stranger to political and economic instability, has during the last year experienced a heightened level of social unrest and resentment toward the government in Port-au-Prince. This echoes the unrest present when the Haitian president, Jean Vilbrun Guillaume Sam, was assassinated, prompting the arrival of the U.S. Marines to restore order on 28 July

Christopher Davis is currently a lecturer in the Department of History at the University of North Carolina at Greensboro. He teaches courses on world history during the early twentieth century and on the history of the First World War. His research primarily focuses on the history of U.S. intervention in the Caribbean and Latin America during the early twentieth century, as well as U.S. engagement in the First World War. 
1915. Between 1911 and 1915, Haiti experienced its historically highest level of chronic political instability when as many as seven different presidents were either overthrown or assassinated while in office. ${ }^{1}$ While not experiencing such an extreme turnover rate in its leaders currently, the Haitian government at present once again faces the possibility of being violently overthrown by an increasingly frustrated populace.

In light of the recent buildup of U.S. military forces in the Caribbean region to counter events in Venezuela, the potential lessons of past operations in the region can be all the more pertinent going forward. With regional stability there once again in question, the history of the area and the individual nations within it is a resource by which to develop successful tactics and strategies and avoid repeating missteps. The goal of this article is to demonstrate the role of Haitian history in the insurgencies against the U.S. occupation between 1915 and 1934, and why the failure to account for that history exacerbated those movements. Also demonstrated will be how the U.S. Marine Corps successfully adapted its approach to unconventional warfare as a result of these conflicts. In so doing, the argument will be made that the work of military innovation, whose focus is understandably toward the future, can benefit considerably from looking backward as well. The history of the U.S. occupation of Haiti during the previous century serves as a useful case study in how history can be an enemy when it is overlooked and a valuable teacher when understood.

The current crisis in Haiti stems from government corruption, and while that is not new for Haiti, the scope of that corruption and the hardships placed on the Haitian people as a consequence of it is new. In 2005, when global oil prices reached record levels, Venezuelan president Hugo Chavez used the country's vast oil supply (then producing around 2.5 million barrels a day) in an attempt to extend Venezuela's influence in the region, and thereby court potential allies against the United States. The program, known as PetroCaribe, was designed to improve the development of participant nations by loaning them oil at a low interest rate, and deferring payment on 40 percent of the oil purchased for up to 25 years. Those nations could then sell the oil elsewhere and use the proceeds for social programs. ${ }^{2}$ The hope was that participating nations, Haiti being among them, would benefit from this arrangement and that the government would use these funds from the oil revenue to improve the nation's infrastructure. This was not the case.

Much has changed for both Venezuela and Haiti since 2005 and, in both cases, not for the better. By 2014, years of mismanagement and corruption by the Venezuelan government came to the forefront as global oil prices dropped, and their economy collapsed. As of 2019, in spite of the nation's vast oil supply, Venezuelan oil production has dropped to a mere 830,000 barrels per day. Haiti in that time has seen its own share of troubles, particularly from the devastat- 
ing earthquake that hit the capital of Port-au-Prince in January 2010. While the PetroCaribe program was still running, the Haitian government claimed to have used nearly $\$ 4$ billion raised between 2008 and 2016 for around 400 infrastructure and health-care programs in the wake of the disaster. However, as time passed, little measurable progress could be detected in these areas despite the money supposedly invested in them. This was already a source of frustration for Haitians, and by 2017, suspicions of wrongdoing resulted in a five-person commission in the Haitian Senate, whose investigation uncovered that the amount of money in the government's coffers were misreported, exchange rates had been adjusted, and that more than one-half of the contracts awarded by the government to companies did not go through the usual bidding process. ${ }^{3}$

The situation in Haiti quickly began to unravel after this discovery. As inflation dramatically increased, and the flow of oil from Venezuela continued to slow, the Haitian government's plan to raise fuel taxes in response provoked violent protests as early as 2018. When Venezuela suspended the PetroCaribe program in 2019, in response to the suffering from its own economic collapse, the combination of government corruption, fuel shortages, and massive inflation triggered a surge of antigovernment protests in Haiti that are still active today. ${ }^{4}$ Not only do these protests currently show little sign of abating, but the government opposition has already expanded the list of those it blames for the current crisis. While much of the public outrage is directed toward Haitian president Jovenel Moise for his involvement in the PetroCaribe scandal, despite meetings between American officials and the Moise government to address the nation's crisis and offers to meet with Haitian opposition leaders as well, some protestors have accused the United States of supporting the Moise government. ${ }^{5}$ One of the more dramatic displays of these protestors against perceived U.S. interference was caught on video in November 2019, when protestors sacrificed a pig outside of the U.S. embassy. ${ }^{6}$

\section{History of Haiti, the Haitian Revolution, and U.S. Interventions}

What little media attention this display received seems to have dismissed the act as a mere eccentricity, but herein lies the danger of engaging with — and drawing conclusions concerning - a people while unfamiliar with their history. A rich historiography exists to inform and clarify the events of the Haitian Revolution, such as Philippe Girard's Haiti: The Tumultuous History, Laurent Dubois's Haiti: The Aftershocks of History, and David Geggus's The Haitian Revolution: A Documentary History to name a few. ${ }^{7}$ According to Haitian tradition, the revolution that resulted in Haitian independence by 1804 began in August 1791, when a spiritual leader named Dutty Boukman and several other slaves (either African or of African descent) performed a ritual of sacrificing a black pig while forging 
a pact of revenge against the French slaveholders. ${ }^{8}$ In all likelihood, what came across to those reporting on this more recent incident as an eccentric display was in reality the recreation of a ritual from the Haitian past that is as significant to their history as the first shot fired at Lexington, Massachusetts, was to our own revolutionary history. It is perhaps fair to speculate that these protestors were making a call for a new revolution against the Moise government and the U.S. presence in Haiti. At this point, no such revolution has materialized in spite of continued protests. Nevertheless, this incident highlights how lack of familiarity with a nation's history can blind us from understanding the deeper meaning, and the motivational factors of, local resistance to U.S. presence.

As the crisis in Haiti continues to unfold, and the United States attempts to navigate the situation, it is important to understand how Haitian history, and particularly our lack of understanding of it, has challenged American policy in the past. The occupation of Haiti by the U.S. Marines between 1915 and 1934 was a time of innovation, in which the Marine Corps developed counterinsurgency tactics that differed significantly from the conventional warfare being waged along the western front of World War I. It was also a time of administrative missteps that fueled resistance and resentment to the U.S. presence that could otherwise have been avoided, or at the very least significantly diminished.

\section{The Price of Efficiency}

What can the case study of Haiti between 1915 and 1934 teach us about military innovation in 2020? Though this event occurred a century ago, many of the conflicts that the United States has been engaged with since the occupation of Haiti have likewise been asymmetrical conflicts against opponents utilizing guerrilla rather than conventional warfare. Therefore, there are valuable lessons to be learned from previous conflicts in which the better trained, equipped, and efficient U.S. military was harassed by a guerrilla-style organization. One finds it hard to make an argument against efficiency as it is a vital component of any and all successful military operations. Nevertheless, what the occupation of Haiti demonstrates is that efficiency, carried out without consideration for its potential impact, can undermine the overall goal. In the case of Haiti between 1915 and 1934, the efficiency of the Marines in establishing order and streamlining state infrastructure projects failed to take into account how Haitian history had shaped the way Haitians would respond to these projects. In her book The Marines, Counterinsurgency, and Strategic Culture, Jeannie L. Johnson examines the nation-building efforts of the Marines in Haiti and how the emphasis on efficiency was both a strength and a weakness of their efforts. ${ }^{9}$ From the perspective of the Marines, the inability of the Haitian government to effectively and efficiently exert its authority across the state was the greatest contributing factor to its chronic instability. ${ }^{10}$ For Haiti to be stable, the gov- 
ernment needed to be able to assert control beyond the confines of the capital, Port-au-Prince. The Marines set out with the goal of creating the means for greater centralized political authority, and it did so by focusing on improving the country's infrastructure, allowing for greater transportation across Haiti, as well as forming a local security force trained by the Marines known as the Gendarmerie. ${ }^{11}$ At first, these could be viewed as early successes of the occupation as it succeeded in giving the Haitian government enhanced ability to enforce its will outside of the capital.

Johnson's conclusion is that this approach favoring efficiency above other concerns resulted in negative long-term consequences. While the Marines succeeded in creating the means for the Haitian government to centralize and project its authority during and after the U.S. intervention, Johnson argues that this success undermined the intended goal of nation-building. Johnson makes a distinction between nation-building and state-building in that, while the Marines succeeded in building the efficiency of the Haitian state in certain aspects, such as infrastructure and security, it did not devote adequate attention to nation-building activities such as fostering democratic institutions and building positive relations with the Haitian people. ${ }^{12}$ Her conclusion is that improving the Haitian state's ability to project authority at the expense of fostering democracy during the U.S. occupation laid the groundwork for post-occupation Haitian dictatorships such as the Duvalier regime to maintain and abuse their authority. ${ }^{13}$ The goal of the Marines to prioritize establishing long-term centralized authority in Haiti during the occupation was also stated in the September 1931 issue of Leatherneck. In an article entitled, "The Garde d'Haiti," the author recalls the initial goals of the occupation: assume police and city government duties in Port-au-Prince before working to establish the Gendarmerie to assume these duties once the Marines left. ${ }^{14}$ While the establishment of centralized authority in Port-au-Prince can be viewed as a success of the U.S. occupation, the long-term consequences of this for Haitians contrasted the Marines' intentions. The intent was order and stability, but the long-term result was a better infrastructure for future authoritarianism.

\section{Post-Occupation Consequences: Lessons Learned from Haiti}

While Johnson's argument provides an example of what Haitian history can teach us in terms of nation-building versus state-building, the focus of this argument is limited to the post-occupation consequences. Therefore, additional focus needs to be applied to how Haitian history impacted the intervention itself and what lessons this can teach about the role of history in the execution of military interventions. Indicative of the problem faced by the Marines during the occupation by not understanding Haitian history was their attempts to 
win over the population. Believing that resistance to the U.S. presence resulted from ignorance of its motives and intentions, the Marines' policy to address this was to appoint prominent native civilians as proxy ambassadors to explain why Haitians should support U.S. involvement. ${ }^{15}$ While this may have been the right idea, in the case of Haiti, it was not properly applied and ultimately did not address the real problem. The real source of increasing Haitian resistance against the U.S. presence stemmed from the Marines enacting an outdated and controversial Haitian law that, while intended to increase the efficiency of the Haitian infrastructure and economy, instead solidified Haitian fears that the slavery their ancestors had fought against had returned.

Shortly after taking control of Port-au-Prince in July 1915, the Marines followed up by deploying companies in Cap-Haitien, Les Cayes, Jeremie, Portde-Paix, and Saint-Marc. ${ }^{16}$ In taking these key positions across Haiti, what remained was the mountainous terrain of the north between the port cities of Saint-Marc, Port-de-Paix, and Cap-Haitien. Completing the infrastructure needed to connect Port-au-Prince to these northern ports meant building railroads through this region. To accomplish this task, the Marines looked to Haitian history as a means of streamlining the project, but in this case misapplied it in a way that sharply increased Haitian resistance. The policy in question was known as the corvée. The corvée was a tradition going as far back as the Haitian revolutionary leaders Toussaint L'Ouverture and Jean-Jacques Dessalines who had attempted to rebuild the Haitian economy after that conflict. It was a nineteenth-century law in which the Haitian state could require citizens to participate in plantation work or road repair without compensation. ${ }^{17}$ By 1917 , as U.S. efforts in Haitian nation-building had similar objectives, Major Smedley D. Butler advocated for the resurrection of this defunct Haitian law. ${ }^{18}$

On its surface, the application of a Haitian law for the purpose of improving infrastructure in Haiti would appear to have been a reasonable and efficient approach to the situation. However, this decision represents the primary catalyst for increased local insurgency and popular resentment in Haiti as well as, over time, increased resentment within the U.S. population and government toward the occupation. It also represents the key example of this article in how not understanding the history of the population being engaged by U.S. nationbuilding efforts can ultimately undermine those efforts. When this approach was applied by the Haitian leaders in the aftermath of the revolution, despite the fact that this enforced labor now included payment, it was not well-received by a population of former slaves who were not keen to work the plantations from which they had already been liberated. ${ }^{19}$ This policy had been defunct since the previous century for a reason. The Haitian peasantry had been resistant to the idea of coerced labor even when their own government had imposed it.

What Butler advocated in 1917 was found to be even more unpalatable to 
the Haitian populace. To increase the rate of infrastructure development without further taxing the limited budget of the Gendarmerie, the corvée applied in this case was unpaid labor that appeared optional. ${ }^{20}$ Gendarmes would notify peasants who had been selected for service that they either had to work on the roads or pay a tax, but this was not a real choice for a population who had no money with which to pay such a tax. ${ }^{21}$ In this case, efficiency came at the cost of Haitian public support, or at least acceptance, of the U.S. presence. Whereas Butler saw a means of efficiently streamlining U.S. goals, the Haitians, a people whose nation had been formed by African slaves after resisting and overthrowing a foreign, Western power (France), saw something very different: the return of slavery and therefore a direct threat to Haitian national identity and freedom.

\section{Haitian Resistance to U.S. Occupation}

By 1918, the result was a drastic escalation in local resistance, particularly in the northern region, compared to what the Marines had encountered in the initial revolt immediately following the 1915 intervention. During the U.S. occupation of Haiti, Marine forces repelled two revolts that became known as the cacos revolts, with the first occurring in 1915 and the second between 1918 and 1920. The first caco revolt of 1915 began as part of the initial, and not unexpected, reaction of certain groups to the U.S. takeover of Port-au-Prince. Cacos was a term for Haitian resistance fighters, typically consisting of peasants operating in the northern mountain region, where generations of aspiring and would-be leaders recruited to overthrow the government in Port-au-Prince. ${ }^{22}$ In 1915, opposition leader Rosalvo Bobo maintained this tradition as he and his caco army orchestrated the presidential assassination that triggered U.S. intervention. And it was this insurrectionary force that turned its energies toward the Marines once the United States determined that Bobo would not be allowed to control the successive Haitian government. ${ }^{23}$

During this initial revolt against the U.S. presence in Haiti, the Marines were able to capitalize on the fact that, regardless of how Haitians viewed that presence in relation to their nation's sovereignty, the cacos enjoyed little support from the Haitian public. After four years of worsening chronic instability, many Haitians were more resentful of the cacos as they, not the Americans, had been the ones attacking farms, raiding stores and supplies, and robbing women on their way to town as part of their insurrections. ${ }^{24}$ The wedge between the Haitian public and insurgents provided a decisive advantage for the Marines in terms of public relations. The result was that this revolt was short-lived and quickly curtailed as the Marines successfully adapted its strategy to counterinsurgency (which will be discussed further in the following section). The second caco revolt, however, was the result of far more widespread resentment to the continued U.S. presence, primarily in response to the corvée. Along with stok- 
ing the historical fears of the Haitians of a foreign military force returning them into slavery, as well as carrying out this policy largely in the northern mountains where, historically, caco resistance had been strongest, it soon became clear that the corvée allowed opportunities for abuse. Most of these abuses appear to have occurred by the Haitian Gendarmes themselves in instances where they exempted some from service in exchange for bribes while others were impressed into service, and sometimes reimpressed even after having served their designated time. ${ }^{25}$ These abuses largely occurred in the north under Major Clark H. Wells, who in 1920 was relieved of his command after then-Brigadier General George Barnett had discovered Wells had falsified reports to cover them up. ${ }^{26}$ Along with a military investigation, the U.S. press soon picked up stories of "indiscriminate killings" in Haiti, which in turn fueled a congressional investigation into the occupation itself. ${ }^{27}$

Accounts from American missionaries and local clergy, who were initially supportive of the U.S. occupation, reveal an assessment of the situation and how the image of the Marines among the Haitians had been negatively impacted by the corvée. In a letter to the U.S. Department of State from a Catholic bishop in the north of Haiti, Monseigneur Keruzan, described various brutalities carried out against the Haitian population there. While asserting that the majority of these acts committed during the corvée were by the Haitian Gendarmes and not the American Marines, it had caused "universal anger and resentment against the Americans." They believed that more should have been done to restrain the Gendarmes under their command, and that the enforcement of the corvée "by the authority of the whites, seem to them (Haitians) as a species of slavery." 28 The corvée was soon abolished, but the damage to the U.S. image had been done and resentment to the American presence in Haiti continued even after the second revolt had been suppressed and the abuses brought to an end.

In both the first and second caco revolts, the Marines were able to successfully defeat the insurgencies. However, while the first revolt in 1915 was a reactionary movement by a group loyal to a specific leader with very limited support from the rest of the Haitian population, the second revolt was a consequence of a policy that failed to take into account the history of the people in question. For the sake of efficiency, an outdated Haitian law was utilized without consideration for how a program of coerced, unpaid labor by a foreign military of white officers would be received by a people whose national identity was forged in resisting slavery and forced labor. Had the history of Haiti and how it shaped Haitian cultural and national identity been given greater consideration, the sharp increase in resistance and resentment to the U.S. presence in Haiti after 1917 could potentially have been avoided. Sadly, this pattern would be repeated in later conflicts such as Vietnam. As a result, while the Marines were able to defeat the second caco movement, they could not regain the pub- 
lic support, or at least acquiescence, of their presence they enjoyed before the corvée was implemented.

\section{Innovations in Nonconventional Warfare}

In spite of the consequences of the use of the corvée, Marine tactics and strategy evolved from pursuing a conventional warfare approach to one better suited for the irregular warfare experienced in Haiti and elsewhere. During the first caco revolt in 1915, along with limited public support of the cacos themselves, the Marines had the additional advantages of state-of-the-art rifles and machine gun technology, compared to an opponent armed with antiquated rifles, pikes, and/or machetes. ${ }^{29}$ Although the cacos had greater familiarity with the terrain, this did little against the superior training and technology utilized by the Marines. Though disarmament through negotiation was the preferred method of dealing with caco resistance, the Marines used patrols conducting hunt-and-kill operations to eliminate the cacos they encountered. ${ }^{30}$ Some of these sweeps were done with intelligence gathered from the local communities, in which Haitian prostitutes became valuable informants on who in town was and was not a caco. ${ }^{31}$ This effective combination of training, technological superiority, use of patrols, and intelligence gathering resulted in very few causalities for the Marines compared to the extremely high causality rate of the cacos.

During the second caco revolt (1918-20), which experienced higher and more prolonged levels of insurgency, these small-patrol tactics evolved further. The one-sided engagements from the previous caco revolt had resulted in a doubling down of the caco strategy to avoid direct engagement with the Marines and focus more on quick strike and retreat operations, particularly disrupting supply lines. ${ }^{32}$ To more effectively draw the enemy out into the open, the Marines in Haiti, as well as in U.S.-occupied Nicaragua and the Dominican Republic, employed a strategy of using their patrols as bait. They would entice the cacos to engage a seemingly small force, thereby bringing them into the line of sight of expert marksmen. ${ }^{33}$ The Marines effectively retooled the caco strategy of limited and disruptive engagement and applied it against the caco infrastructure. By using small, aggressive, and relentless patrols to keep the cacos off-balance and constantly on the run, the Marines' strategy developed here disrupted and eroded the flow of information through the insurgent's organization. ${ }^{34}$ Such tactical and strategic developments in Haiti and other parts of the region during this time would later be codified in The Small Wars Manual (originally published in 1940), in which the lessons learned from these events became Marine doctrine in nonconventional conflicts:

Above all, an active and aggressive campaign against the hostile forces in the field is the most effective method of destroying their intelligence service. A guerrilla band which is constant- 
ly harassed and driven from place to place soon loses contact with its own sources of information; it becomes confused and its intelligence system breaks down. As the occupation continues, superiority in this respect will gradually be obtained by the intervening forces. ${ }^{35}$

The Small Wars Manual stated this as part of how Marines should assess and effectively dismantle the organization of an unconventional enemy.

\section{Conclusions}

In analyzing these events and how the Marines adapted their tactics for the kind of conflict encountered, we see the early stages of development for the tactics that are more applicable to the more recent conflicts in which the United States has been engaged. Johnson's description of the development of the aggressive, small patrol tactics during the Banana Wars is one of Marines in three different theaters-Haiti, the Dominican Republic, and Nicaragua—reaching the same conclusions independently of each other. ${ }^{36}$ Originally beginning these operations based on the conventional strategy of garrisoning the major population centers as strategic defensive points, the Marines recognized in each theater that this approach needed to be modified for a different kind of conflict. ${ }^{37}$ This demonstrated the high capacity for the Marines to adapt to situational realities, yet it also demonstrated another important skill: the ability to let your enemy teach you how to defeat them. As the cacos utilized hit-and-run strikes and a focus on the disruption of U.S. supply lines, the Marines in turn applied a modified version of this strategy against them. By using small patrols to lure cacos into engagements and applying these patrols aggressively to keep their supply and organizational intelligence off-balance, the Marines combined their enemy's most effective tactics, which were better suited to the terrain, with the Marine's own superior training and weapons technology. This approach of using what works for a specific enemy and modifying those tactics to include the Marines' preexisting advantages offers the ability to innovate tactics and strategies tailored to specific opponents.

The case of Haiti during the early twentieth century also demonstrates that history can be an enemy as well. Not being familiar with the history of a specific people and how that history has shaped their culture can have real consequences in which missteps in administrative policy can occur, unnecessarily creating heightened resistance and resentment from the indigenous population. What the United States effectively did by instituting the corvée was trigger the worst fears of the Haitian people based on their historical experience, resulting in an armed backlash and loss of whatever goodwill the United States originally had with the populace. Even worse, without understanding the history of the corvée 
in Haiti and how it would be perceived when instituted by a foreign force of white officers, the Marines then found themselves having to put down a movement without even understanding what was causing it. Innovation has been shown to occur when we learn from the enemy's strategies, and the case of Haiti in 1915-34 has shown that history should be allowed to do the same. Whatever the near future holds for Haiti and other nations in the region that are facing increasing popular unrest and decreasing political stability, understanding the individual histories of these places is essential to successfully develop any and all approaches the United States may undertake to navigate these issues.

\section{Endnotes}

1. "Milestones: 1914-1920-The U.S. Invasion and Occupation of Haiti, 1915-1934," Department of State, Office of the Historian, accessed 18 May 2020.

2. Ciara Nugent, "Why a Venezuelan Oil Program Is Fueling Massive Street Protests in Haiti," Time, 24 June 2019.

3. Nugent, "Why a Venezuelan Oil Program Is Fueling Massive Street Protests in Haiti."

4. Nugent, "Why a Venezuelan Oil Program Is Fueling Massive Street Protests in Haiti."

5. Marco Dubois, "Haiti's Opposition Leaders Announced More Protests in 2020," Neighbor News, 3 January 2020.

6. "Haitians Want Their Freedom from U.S. Embassy," LifeZette, video, 4:07, 9 December 2019.

7. Philippe Girard, Haiti: The Tumultuous History_From Pearl of the Caribbean to Broken Nation (New York: Palgrave Macmillan, 2010); Laurent Dubois, Haiti: The Aftershocks of History (New York: Picador, 2012); and David Geggus, The Haitian Revolution: A Documentary History (Indianapolis: Hackett Publishing, 2014).

8. Laurent Dubois, Avengers of the New World: The Stories of the Haitian Revolution (Cambridge, MA: Belknap Press, an imprint of Harvard University Press, 2004), 99-100.

9. Jeannie L. Johnson, The Marines, Counterinsurgency, and Strategic Culture: Lessons Learned and Lost in America's War (Washington, DC: Georgetown University Press, 2018).

10. Johnson, The Marines, Counterinsurgency, and Strategic Culture, 185.

11. Johnson, The Marines, Counterinsurgency, and Strategic Culture, 185.

12. Johnson, The Marines, Counterinsurgency, and Strategic Culture, 189.

13. Johnson, The Marines, Counterinsurgency, and Strategic Culture, 185.

14. Anonymous, "The Garde d'Haiti," Leatherneck 14, no. 9, September 1931, 9.

15. Johnson, The Marines, Counterinsurgency, and Strategic Culture, 189.

16. Lester D. Langley, The Banana War: An Inner History of American Empire, 1900-1934 (Lexington: University Press of Kentucky, 1983).

17. Langley, The Banana War, 59.

18. Langley, The Banana War.

19. Christopher W. Davis, "Cross Purposes: U.S. Missionaries and the U.S. Occupation of Haiti” (PhD diss., University of North Carolina at Greensboro, 2019), 36.

20. Langley, The Banana War, 159-60.

21. Langley, The Banana War, 160.

22. Lester D. Langley, The United States and the Caribbean in the Twentieth Century, 4th ed. (Athens: University of Georgia Press, 1989), 74.

23. Hans Schmidt, The United States Occupation Haiti, 1915-1934 (New Brunswick, NJ: Rutgers University Press, 1995), 71-72.

24. Laurent Dubois, Haiti: The Aftershocks of History (New York: Picador, 2012), 227. 
25. Langley, The Banana War, 160.

26. Robert Debs Heinl Jr. and Nancy Gordon Heinl, Written in Blood: The Story of the Haitian People, 1492-1971 (Boston: Houghton Mifflin, 1978), 463-64.

27. Davis, "Cross Purposes," 207.

28. Monseigneur Keruzan, "Bishop Keruzan to Robert Lansing, September 17, 1918," file 838.00/1551, Record Group 59, National Archives, College Park, MD.

29. Dubois, Haiti, 229.

30. Schmidt, The United States Occupation Haiti, 84.

31. Mary A. Renda, Taking Haiti: Military Occupation \& the Culture of U.S. Imperialism, 1915-1940 (Chapel Hill: University of North Carolina Press, 2001), 171.

32. Dubois, Haiti, 229.

33. Johnson, The Marines, Counterinsurgency, and Strategic Culture, 207.

34. Johnson, The Marines, Counterinsurgency, and Strategic Culture, 207.

35. Small Wars Manual (Washington, DC: Headquarters Marine Corps, 1990), 2-3.

36. Johnson, The Marines, Counterinsurgency, and Strategic Culture, 202.

37. Johnson, The Marines, Counterinsurgency, and Strategic Culture, 206. 